\title{
Neural Activity Is Modulated by Trial History: A Functional Magnetic Resonance Imaging Study of the Effects of a Previous Antisaccade
}

\author{
Dara S. Manoach, ${ }^{1,3}$ Katherine N. Thakkar, ${ }^{1}$ Matthew S. Cain, ${ }^{1}$ Frida E. Polli, ${ }^{1}$ Jay A. Edelman, ${ }^{4}$ Bruce Fischl,,${ }^{2,3}$ and \\ Jason J. S. Barton ${ }^{5}$ \\ Departments of ${ }^{1}$ Psychiatry and ${ }^{2}$ Radiology, Massachusetts General Hospital, and ${ }^{3}$ Athinoula A. Martinos Center for Biomedical Imaging, Harvard Medical \\ School, Boston, Massachusetts 02129, ${ }^{4}$ Department of Biology, The City College of New York, New York, New York 10031, and ${ }^{5}$ Departments of Neurology, \\ Ophthalmology, and Visual Sciences, University of British Columbia, Vancouver, British Columbia, Canada V5Z 3N9
}

\begin{abstract}
Saccadic latencies are influenced by what occurred during the previous trial. When the previous trial is an antisaccade, the latencies of both prosaccades and antisaccades are prolonged. The aim of this study was to identify neural correlates of this intertrial effect of antisaccades. Specifically, based on both monkey electrophysiology and human neuroimaging findings, we expected trials preceded by antisaccades to be associated with reduced frontal eye field (FEF) activity relative to those preceded by prosaccades. Twenty-one healthy participants performed pseudorandom sequences of prosaccade and antisaccade trials during functional magnetic resonance imaging (fMRI) with concurrent monitoring of eye position. We compared activity in trials preceded by an antisaccade with activity in trials preceded by a prosaccade. The primary result was that a previous antisaccade prolonged saccadic latency and reduced fMRI activity in the FEF and other regions. No regions showed increased activity. We interpret the reduced FEF activity and slower saccadic responses to reflect inhibitory influences on the response system as a consequence of performing an antisaccade in the previous trial. This demonstrates that neural activity is modulated by trial history, consistent with a rapid, dynamic form of learning. More generally, these results highlight the importance of trial history as a source of variability in both behavioral and neuroimaging studies.
\end{abstract}

Key words: plasticity; antisaccade; frontal eye field; functional neuroimaging; context; cognition

\section{Introduction}

Optimizing behavior depends on the ongoing adjustment of responses based on the context in which they occur. Although most behavioral studies focus on the effects of immediate task conditions, responses also depend on what occurred during the previous trial (Fecteau and Munoz, 2003). Behavioral studies demonstrate that saccadic performance is influenced by the previous saccade. In particular, compared with a previous prosaccade, performing an antisaccade in the previous trial prolongs the latencies of both prosaccades and antisaccades (Cherkasova et al., 2002; Fecteau et al., 2004; Barton et al., 2006). Whereas prosaccades require a gaze toward a suddenly appearing visual target, antisaccades require inhibition of the prepotent prosaccade and the generation of a saccade away from the target (Hallett, 1978).

What accounts for the previous antisaccade effect on latency?

Received March 16, 2006; revised Jan. 16, 2007; accepted Jan. 17, 2007.

This work was supported by the National Institute of Mental Health (R01 MH67720, F21 MH72120), the Mental IIIness Neuroscience Discovery Institute (DOE DE-FG02-99ER62764), the National Center for Research Resources (P41 RR14075, R01 RR16594, BIRN002, U24 RR021382), the National Institute for Biomedical Imaging and Bioengineering (R01 EB001550), and the National Institute of Neurological Disorders and Stroke (R01 NS052585-01). We thank Randy Buckner, Mark Vangel, Douglas Greve, and two anonymous reviewers for invaluable suggestions and Lawrence Wald, Raynald Comtois, Szymon Mikulski, and Jill Clark for technical assistance.

Correspondence should be addressed to Dara S. Manoach, Massachusetts General Hospital, 149 13th Street, Room 2608, Charlestown, MA 02129. E-mail: dara@nmr.mgh.harvard.edu.

DOI:10.1523/JNEUROSCI.3662-06.2007

Copyright $\odot 2007$ Society for Neuroscience $\quad$ 0270-6474/07/271791-08\$15.00/0
One possibility is that it reflects alterations in preparatory activity in ocular motor regions. In monkey electrophysiology studies, compared with a prosaccade, an antisaccade is associated with reduced pretarget activity of saccade-related neurons in the frontal eye field (FEF) (Everling and Munoz, 2000) and superior colliculus (Everling et al., 1999). Moreover, lower pretarget FEF activity is correlated with increased saccadic latency and fewer antisaccade errors. If an antisaccade command has persistent effects and reduces preparatory activity in the FEF not only in the current trial but also in the subsequent one, then this could increase the latency of the subsequent saccade (Barton et al., 2006).

Other aspects of saccades influence physiological and behavioral characteristics of the subsequent saccade. For example, in a monkey study requiring saccades to the right or left, latencies were shorter if a saccade was in the same direction as the previous saccade (Dorris et al., 2000). This latency effect was paralleled in the superior colliculus by greater pretarget activity if the saccade of the previous trial was in the preferred direction of the neuron. This phenomenon was labeled "immediate neural plasticity," because it indicated that neural activity could be shaped by experience in a continuous, dynamic manner. Similar intertrial effects of saccades have been observed in the FEF (Bichot and Schall, 2002). In the present study, we reasoned that because the direction of the previous response can affect subsequent pretarget activity, the powerful inhibition generated by a previous antisac- 
cade might also persist in the saccadic system as another type of response-system "plasticity."

We used event-related functional magnetic resonance imaging (fMRI) to examine the neural basis of the previous antisaccade effect on latency. Participants performed a pseudorandom series of prosaccades and antisaccades. We contrasted the effect of a preceding antisaccade with that of a preceding prosaccade on current trials. We hypothesized that a previous antisaccade would be associated with reduced FEF activity in the period preceding target appearance. This hypothesis is based on electrophysiology and fMRI findings that reduced FEF activity is associated with longer saccadic latencies (Everling and Munoz, 2000; Connolly et al., 2004) and findings of reduced fMRI activity during manual responses that were preceded by inhibition ("no-go") versus "go" trials (Durston et al., 2002).

\section{Materials and Methods \\ Sample}

Twenty-one healthy participants (eight females; mean age, $34.2 \pm 12.6$ years) were recruited by poster and website advertisements from the Massachusetts General Hospital and Boston communities. All participants were strongly right handed (mean modified Edinburgh score, $90.5 \pm 11.5$ ) (Schachter, 1994). The study was approved by the Partners Human Research Committee, and all subjects gave written informed consent.

\section{Saccadic paradigm}

Before scanning, the task was explained, and participants practiced until they were comfortable. Participants were encouraged to respond as quickly and accurately as possible. They received five cents for each correct response, an incentive intended to enhance attention and motivation. Each task run lasted $5 \mathrm{~min}, 22 \mathrm{~s}$ and consisted of a pseudorandom sequence of prosaccade trials (range of 32-40 trials per run), antisaccade trials (29-37), and intervals of fixation (9-17). The prosaccade and antisaccade trials were balanced for right and left movements. Figure 1 provides a graphic depiction of the task and a description of task parameters. Fixation intervals lasted $0 \mathrm{~s}$ (i.e., no fixation interval, the next trial started immediately), $2 \mathrm{~s}, 4 \mathrm{~s}$, or $6 \mathrm{~s}$. The fixation intervals provided a baseline, and their variable length introduced "temporal jitter," which optimizes the analysis of rapid presentation event-related fMRI designs (Buckner et al., 1998; Burock and Dale, 2000; Miezin et al., 2000). The schedule of events was determined using a technique to optimize the statistical efficiency of event-related designs (Dale, 1999). Participants performed six runs of the task, with short rests between runs. The total experiment lasted $\sim 40 \mathrm{~min}$ and generated a total of 211 prosaccade and 211 antisaccade trials.

\section{Stimulus display and eye tracking}

Displays of the eye movement task were generated by an Apple Power Mac G4 (Apple Computer, Cupertino, CA), using programs written in $\mathrm{C}++$ on the Vision Shell programming platform, and back projected with a Sharp (Osaka, Japan) XG-2000 color liquid crystal display projector onto a screen positioned on the head coil. The ISCAN (Burlington, MA) fMRI Remote Eye Tracking Laboratory recorded saccades during scanning. This system used a video camera mounted at the rear of the MRI bore. The camera imaged the eye of the supine participant via an optical combiner, a $45^{\circ}$ cold transmissive mirror that reflects an infrared image of the eye, the infrared illumination being provided by a small light-emitting diode cluster mounted on the head coil. The system used passive optical components with no ferrous content within the bore to minimize artifacts in the MR images. Vision Shell triggered the scanner to begin acquiring data. Stimuli presented by Vision Shell were digitally encoded and relayed to ISCAN as triggers that were inserted into the eye movement recordings. Eye images were processed by an ISCAN RK726PCI high-resolution pupil/corneal reflection tracker, located outside of the shielded MRI room. Eye position was sampled at a rate of $60 \mathrm{~Hz}$.

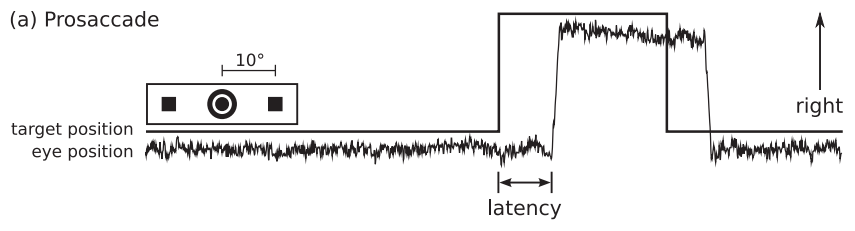

(b) Antisaccade

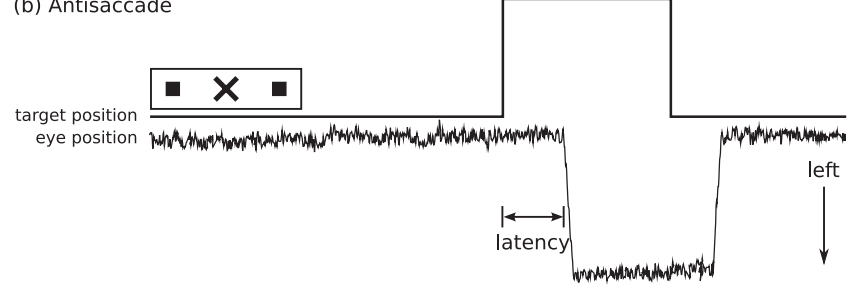

(c) Timeline

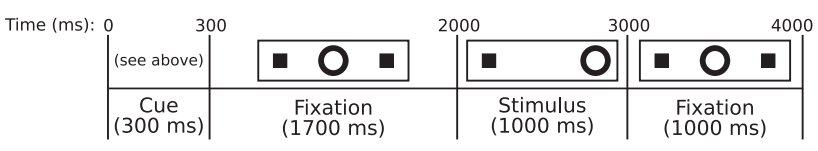

Figure 1. Saccadic paradigm with idealized eye position traces. Saccadic trials lasted 4000 ms and began with an instructional cue at the center of the screen. $\boldsymbol{a}, \boldsymbol{b}$, For half of the participants, orange concentric rings were the cue for a prosaccade trial $(\boldsymbol{a})$ and a blue X was the cue for an antisaccade trial $(\boldsymbol{b})$. These cues were reversed for the rest of the participants. The cue was flanked horizontally by two small green squares of $0.2^{\circ}$ width that marked the potential locations of targets, $10^{\circ}$ left and right of center. These squares remained on the screen for the duration of each run. $c$, At $300 \mathrm{~ms}$, the instructional cue was replaced by a green fixation ring at the center of the screen, of $0.4^{\circ}$ diameter and luminance of $20 \mathrm{~cd} / \mathrm{m}^{2}$. After $1700 \mathrm{~ms}$, the ring shifted to one of the two target locations, right or left, with equal probability. This was the target to which the participant responded. The green ring remained in the peripheral location for $1000 \mathrm{~ms}$ and then returned to the center, where participants were also to return their gaze for 1000 ms before the start of the next trial. Fixation intervals were simply a continuation of the fixation display that constituted the final second of the previous saccadic trial.

\section{Scoring of eye movement data}

Eye movement data were scored in MATLAB (Mathworks, Natick, MA) using a partially automated program that determined the directional accuracy of each saccade with respect to the required response and the latency from target onset. Saccades were identified as horizontal eye movements with velocities exceeding $47^{\circ} \%$. The onset of a saccade was defined as the point at which the velocity of the eye first exceeded $31 \%$. Only trials with saccades in the desired direction and latencies $>130 \mathrm{~ms}$ were considered correct, and only correct saccades were included in the latency analyses. The cutoff of $130 \mathrm{~ms}$ excluded anticipatory saccades, which are executed too quickly to be a valid response to the appearance of the target (Fischer and Breitmeyer, 1987; Doricchi et al., 1997; Straube et al., 1999).

\section{Image acquisition}

Images were acquired with a 3.0T Siemens (Erlangen, Germany) Trio whole-body high-speed imaging device equipped for echo planar imaging. Head stabilization was achieved with cushioning, and all participants wore earplugs ( $29 \mathrm{~dB}$ rating) to attenuate noise. Automated shimming procedures were performed, and scout images were obtained. Two highresolution structural images were acquired for slice prescription, spatial normalization, and cortical surface reconstruction using a threedimensional (3D) magnetization-prepared rapid gradient echo (MPRAGE) sequence [repetition time (TR), $2530 \mathrm{~ms}$; echo spacing, 7.25 $\mathrm{ms}$; echo time (TE), $3 \mathrm{~ms}$; flip angle, $7^{\circ}$; voxel size, $\left.1.3 \times 1.3 \times 1 \mathrm{~mm}\right]$. T1and $\mathrm{T} 2$-weighted structural images, with the same slice specifications as the blood oxygen level-dependent (BOLD) scans, were obtained to assist in registering functional and structural images. Functional images were collected using a gradient echo T2*-weighted sequence (TR, $2000 \mathrm{~ms}$; TE, $30 \mathrm{~ms}$; flip angle, $90^{\circ}$ ). Twenty contiguous horizontal slices parallel to the intercommissural plane (voxel size, $3.13 \times 3.13 \times 5 \mathrm{~mm}$ ) were acquired interleaved. The functional sequences included prospective acquisition correction (PACE) for head motion (Thesen et al., 2000). PACE adjusts 
slice position and orientation in real time during data acquisition. This reduces motion-induced effects on magnetization history.

\section{Analysis of imaging data}

All analyses were conducted using FreeSurfer (Fischl et al., 1999a) and FreeSurfer Functional Analysis Stream (Burock and Dale, 2000) software. Eight time points at the beginning of each run were acquired and discarded to allow longitudinal magnetization to reach equilibrium and the hemodynamic response to the first trial (which has no historical influences) to return to baseline. In addition to the on-line motion correction (PACE), functional scans were corrected retrospectively for motion using the analysis of functional neuroimages algorithm (Cox and Jesmanowicz, 1999), intensity normalized, and smoothed using a 3D 8 $\mathrm{mm}$ full-width half-maximum Gaussian kernel. Finite impulse response (FIR) estimates (Burock and Dale, 2000; Miezin et al., 2000) of the eventrelated hemodynamic responses were calculated for each of the four trial types [prosaccades preceded by prosaccades (ps/PS), prosaccades preceded by antisaccades (as/PS), antisaccades preceded by prosaccades (ps/ AS), and antisaccades preceded by antisaccades (as/AS)] within participants. This involved using a linear model to provide unbiased estimates of the average signal intensity at each time point for each trial type without making a priori assumptions about the shape of the hemodynamic response. Hemodynamic response estimates were computed at 12 time points with an interval of $2 \mathrm{~s}$ (corresponding to the TR) ranging from $4 \mathrm{~s}$ before the start of a trial to $18 \mathrm{~s}$ after the start. Temporal correlations in the noise were accounted for by prewhitening using a global estimate of the residual error autocorrelation function truncated at $30 \mathrm{~s}$ (Burock and Dale, 2000). Functional images were aligned to the 3D structural image for each participant that was created by averaging the two MPRAGE scans after correcting for motion. Anatomical scans were smoothed using the same parameters as the functional scans. To determine the effect of trial history on the present trial, we contrasted identical trial types that differed with regard to the identity of the previous trial (as/PS vs ps/PS and as/AS vs ps/AS) at time points presumed to reflect pretarget activity $(0,2$, and $4 \mathrm{~s})$. This is based on findings that event-related hemodynamic responses begin $\sim 2 \mathrm{~s}$ after the stimulus (in this case, the instructional cue at $0 \mathrm{~s}$ ) and peak between 4 and $7 \mathrm{~s}$ (Boynton et al., 1996; Dale and Buckner, 1997; Miezin et al., 2000). As a result of the timing of slice acquisition, activity at each time point represents a full $2 \mathrm{~s}$. For example, the zero time point represents hemodynamic activity between 0 and $2 \mathrm{~s}$. Because the target appeared $2 \mathrm{~s}$ into the trial, activity at the $4 \mathrm{~s}$ and, to a lesser extent, $2 \mathrm{~s}$ time points also reflect target-related activity.

\section{Region of interest analyses}

Given our a priori hypothesis, we first conducted region-of-interest (ROI) analyses in the FEF and two other cortical regions involved in saccade generation, the supplementary eye field (SEF) and parietal eye field (PEF). We used a two-step ROI approach to localize these regions based on individual participant anatomy and regional activity in an orthogonal contrast (Curtis and D'Esposito, 2003). This approach avoids signal loss attributable to variability in region location between participants and increases statistical power as a result of signal averaging within participants. By defining these regions in an orthogonal contrast, activity measurements are unbiased with regard to hypotheses concerning trial history. The putative human homologs of the FEF, SEF, and PEF were identified on the unregistered cortical surfaces of each participant using anatomical criteria and functional constraint.

Anatomical criteria. The FEF is located in and around the precentral sulcus and gyrus, beginning approximately at the level of the superior frontal sulcus (Paus, 1996; Koyama et al., 2004). The medial hemispheric surface and cortex below the middle frontal gyrus were not included. The SEF is located in the dorsomedial cortex in and around the paracentral sulcus, superior to the cingulate sulcus, and posterior to the coronal plane passing through the anterior commissure (Berman et al., 1999). The PEF was localized to the intraparietal sulcus (Pierrot-Deseilligny et al., 2003).

Functional constraint. Within these anatomical boundaries, we defined the region of interest as all active vertices in the all-trials versus fixation contrast at $4 \mathrm{~s}$ (the time of peak activity in ocular motor regions) at a threshold of $p<0.05$ (this threshold is used for region identification, not for hypothesis testing). This contrast captures activity in current saccadic trials of either type that might be affected by a previous trial of either type but is unbiased to differences between trial types. This resulted in two ROI labels for each region in each participant, one in each hemisphere. Within these ROI labels, we compared activity for trials preceded by antisaccades versus those preceded by prosaccades at 0,2 , and $4 \mathrm{~s}$ using paired $t$ tests based on a random-effects model.

\section{Exploratory analyses of the cortical surface in the registered group data}

After a priori regional analyses, we investigated activation on the cortical surface in the registered group data to determine whether other regions showed an effect of trial history. To register data across subjects, anatomical and functional scans were spatially normalized using a surface-based spherical coordinate system (Dale et al., 1999; Fischl et al., 1999a,b). The cortical surface-based registration procedure uses a nonrigid alignment algorithm based on sulcal and gyral patterns rather than only intensity information (Fischl et al., 1999b). After the spatial normalization of anatomical and functional scans, the significance of each contrast was tested using a random-effects model in which the mean and SE of the contrast effect size (i.e., differences between hemodynamic response estimates for the conditions being compared) were computed across participants. Statistical activation maps were displayed on a template brain consisting of the averaged cortical surface of an independent sample of 40 adults from the Buckner laboratory at Washington University (St. Louis, MO). Cortical activation was localized using an automated surface-based parcellation system (Fischl et al., 2004).

For all contrasts, we used a significance threshold of $p<0.001$ and a minimum cluster size of $115 \mathrm{~mm}^{2}$. These parameters correct for multiple comparisons and set the overall $p$ level at $<0.05$ on the basis of Monte Carlo simulations using synthesized white Gaussian noise data (Forman et al., 1995). In regions showing a significant historical effect, we derived hemodynamic response time courses from the FIR models by plotting activity at $2 \mathrm{~s}$ intervals for the vertex with the peak task-related signal change, scaled by the error variance (local maxima) for the four different saccadic classes: ps/PS, as/PS, ps/AS, and as/AS. To facilitate comparison with other studies, approximate Talairach coordinates were derived by mapping the surface-based coordinates of group activation peaks back to the original structural volume for each participant, registering the volumes to the Montreal Neurological Institute (MNI305) atlas (Collins et al., 1994), and averaging the MNI305 coordinates that corresponded to the surface peak across participants. The resulting coordinates were transformed to standard Talairach space using an algorithm developed by Matthew Brett (http://imaging.mrc-cbu.cam.ac.uk/imaging/MniTalairach) [for a comparison of the accuracy of localization using surfacebased and Talairach procedures, see Fischl et al. (1999b)].

\section{Antisaccade versus prosaccade contrast}

To determine whether regions showing a historical effect based on trial type were differentially involved in current antisaccade versus prosaccade trials, we also examined activation in this contrast in the registered group data.

\section{Results \\ Behavior}

Latency data were absent for two participants because of technical difficulties during scanning (Fig. 2). Only the latencies of correct, nonanticipatory saccades were included in the behavioral analyses. Fewer than $1 \%$ of trials were anticipatory saccades. Error data were logit transformed before analysis. Compared with prosaccades, antisaccades had longer latencies $\left(F_{(1,18)}=\right.$ 1638.76; $p<0.001)$ and higher error rates $\left(F_{(1,20)}=68.35 ; p<\right.$ $0.001)$. To determine the effect of a previous antisaccade, we only examined the latency and error rate of trials preceded by a correct response because these more accurately reflect the historical influences of interest. As expected, a correctly performed antisaccade in the previous trial slowed latencies $\left(F_{(1,18)}=21.55 ; p<\right.$ 


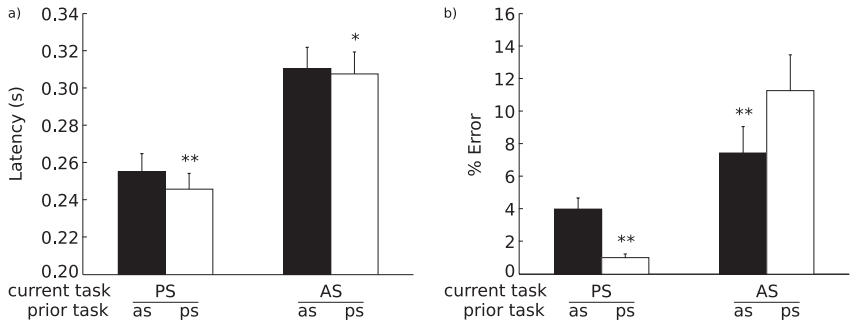

Figure 2. Bar graphs with SE bars of latency in seconds $(\boldsymbol{a})$ and percentage errors $(\boldsymbol{b})$ for current trial type divided by previous trial type. Two asterisks denote statistical significance $(p<0.05)$, and one asterisk denotes a trend $(p<0.10)$. PS, Prosaccades; AS, antisaccades.

0.001). This effect was greater for current prosaccades than current antisaccades (interaction: $F_{(1,18)}=4.53, p<0.05$; prosaccade: $t_{(18)}=4.86, p<0.001$; antisaccade: $\left.t_{(18)}=1.75, p=0.08\right)$. The pattern of findings for accuracy was different. There was no main effect of a previous antisaccade $\left(F_{(1,20)}=1.76 ; p=0.19\right)$. Rather, a previous antisaccade affected antisaccade and prosaccade error rates differently (interaction: $F_{(1,20)}=28.04, p<$ $0.001)$. There were more prosaccade errors $\left(t_{(20)}=4.69 ; p<\right.$ $0.001)$ and fewer antisaccade errors $\left(t_{(20)}=2.80 ; p<0.01\right)$ if the previous trial was an antisaccade. This, too, is consistent with our previous reports indicating a task-switching effect on accuracy and demonstrates divergent effects of trial history on latency and accuracy.

\section{Imaging}

Trial history effects: analyses based on all trials including current and previous errors

Influence of a previous antisaccade on current antisaccades (as/AS vs ps/AS). ROI analyses demonstrated that a previous antisaccade was associated with reduced activity in the following ocular motor regions: bilateral FEF (0, 2, and 4 s), bilateral SEF (right: 0, 2, and $4 \mathrm{~s}$; left, 2 and $4 \mathrm{~s}$ ), and bilateral PEF (2 and $4 \mathrm{~s}$ ) (Table 1). Analyses of registered group data also showed reductions in ocular motor regions, including the bilateral FEF (left, 2 and $4 \mathrm{~s}$; right, $4 \mathrm{~s}$ ), right SEF (2 and $4 \mathrm{~s}$ ), and left PEF (4s) (Fig. 3, Table 2). Additional regions showing reductions were the bilateral orbitofrontal cortex (left: 0,2 , and $4 \mathrm{~s}$; right, 0 and $2 \mathrm{~s}$ ), right insula ( 0 , 2 , and $4 \mathrm{~s}$ ), left posterior cingulate sulcus ( 2 and $4 \mathrm{~s}$ ), left superior parietal gyrus (2s), right superior parietal gyrus (4s), and left precuneus ( $4 \mathrm{~s})$. There were no areas of increased activity.

Influence of a previous antisaccade on current prosaccades (as/PS vs ps/PS). ROI analyses revealed that a previous antisac- cade significantly reduced activity in the bilateral FEF (right, 0 and 2; left, $0 \mathrm{~s}$ ) and right SEF (0 s) (Table 1). In the registered group data, differential activation in ocular motor regions did not reach significance. Other regions that showed significant reductions included the bilateral orbitofrontal cortex (left: 0,2 , and $4 \mathrm{~s}$; right, 0 and $2 \mathrm{~s}$ ), right insula $(0 \mathrm{~s})$, and right middle temporal gyrus (2s) (Table 2).

\section{Control analyses}

Error effects

To exclude the possibility that either current or previous errors account for previous antisaccade effects in our regions of interest, we reanalyzed the data with current error trials and all correct trials preceded by an error modeled as separate events so that they were not included in the contrasts examining trial history. One subject was excluded from this analysis because technical difficulties with eye movement recordings made it impossible to classify a substantial portion of the saccadic trials as correct or erroneous. For current antisaccades, excluding current and previous errors had little effect, suggesting that trial history effects could not be accounted for by errors (Table 1). For current prosaccades, however, excluding current and previous errors eliminated differences in FEF activity, but SEF activity at 0 s continued to differentiate between trials preceded by prosaccades versus antisaccades. In the exploratory analysis of registered group data, significant reductions were also seen in insula and orbitofrontal cortex for antisaccades and in orbitofrontal cortex for prosaccades. There were no areas of increased activity.

Exploratory analysis of current antisaccades versus prosaccades We examined the registered group data to determine whether regions showing a historical effect were differentially involved in current antisaccade versus prosaccade trials. Relative to prosaccades, antisaccades were associated with greater activation in a network of regions important for saccadic execution, including the bilateral FEF, SEF, PEF, and dorsal anterior cingulate cortex (Fig. 4). Table 2 lists regions with significant activation.

\section{Hemodynamic saturation effects}

Because the FEF, SEF, and PEF showed increased activity for antisaccades versus prosaccades, $\mathrm{PMRI}$ activity in these regions in the trial after an antisaccade could be reduced as a result of saturation of the hemodynamic response rather than decreased neural activity (Miezin et al., 2000; Wager et al., 2005). If this were the case, reductions should dissipate with longer intertrial intervals because the hemodynamic response from the previous trial has

Table 1. ROI $t$ test and $p$ values comparing the effect of a previous antisaccade (AS) versus prosaccade (PS) on activity in the FEF, SEF, and PEF of the right and left hemispheres at 0,2 , and $4 \mathrm{~s}$ during current antisaccade and prosaccade trials

\begin{tabular}{|c|c|c|c|c|c|c|c|c|}
\hline & & & \multicolumn{2}{|l|}{ FEF } & \multicolumn{2}{|l|}{ SEF } & \multicolumn{2}{|l|}{ PEF } \\
\hline & & & Left & Right & Left & Right & Left & Right \\
\hline \multirow[t]{6}{*}{ AS } & \multirow[t]{2}{*}{$\mathrm{Os}$} & All trials & $-3.11,0.006^{*}$ & $-2.58,0.02^{*}$ & $-1.84,0.08$ & $-2.12,0.05^{*}$ & $-1.50,0.15$ & $-2.04,0.06$ \\
\hline & & Correct trials & $-2.23,0.04^{*}$ & $-1.30,0.21$ & $-1.75,0.10$ & $-2.28,0.03^{*}$ & $-1.23,0.24$ & $-1.60,0.13$ \\
\hline & \multirow[t]{2}{*}{$2 s$} & All trials & $-4.84,<0.0001^{*}$ & $-3.00,0.007^{*}$ & $-2.08,0.05^{*}$ & $-2.55,0.02^{*}$ & $-2.45,0.02^{*}$ & $-2.44,0.02^{*}$ \\
\hline & & Correct trials & $-4.32,0.0004^{*}$ & $-3.15,0.005^{*}$ & $-3.17,0.005^{*}$ & $-3.09,0.006^{*}$ & $-2.34,0.03^{*}$ & $-2.63,0.02^{*}$ \\
\hline & \multirow[t]{2}{*}{$4 s$} & All trials & $-4.81,0.0001^{*}$ & $-2.71,0.01^{*}$ & $-2.36,0.03^{*}$ & $-2.54,0.02^{*}$ & $-4.51,0.0002^{*}$ & $-3.11,006^{*}$ \\
\hline & & Correct trials & $-4.12,0.0006^{*}$ & $-3.60,0.002^{*}$ & $-3.58,0.002^{*}$ & $-3.06,0.007^{*}$ & $-4.01,0.0008^{*}$ & $-3.64,0.002^{*}$ \\
\hline \multirow[t]{6}{*}{ PS } & \multirow[t]{2}{*}{$0 \mathrm{~s}$} & All trials & $-2.22,0.04^{*}$ & $-3.00,0.007^{*}$ & $-1.23,0.23$ & $-2.43,0.03^{*}$ & $-1.11,0.28$ & $-1.83,0.08$ \\
\hline & & Correct trials & $-1.26,0.22$ & $-0.88,0.39$ & $-0.80,0.43$ & $-2.66,0.02^{*}$ & $-0.65,0.52$ & $-1.18,0.25$ \\
\hline & \multirow[t]{2}{*}{$2 s$} & All trials & $-1.54,0.14$ & $-2.14,0.05^{*}$ & $-0.84,0.41$ & $-1.51,0.15$ & $-0.88,0.39$ & $-1.81,0.09$ \\
\hline & & Correct trials & $0.63,0.54$ & $-0.55,0.59$ & $-0.87,0.39$ & $-1.43,0.17$ & $-0.15,0.88$ & $-1.33,0.20$ \\
\hline & \multirow[t]{2}{*}{$4 \mathrm{~s}$} & All trials & $-0.43,0.67$ & $-0.86,0.40$ & $-0.05,0.96$ & $-1.11,0.28$ & $0.08,0.94$ & $-1.10,0.29$ \\
\hline & & Correct trials & $0.25,0.80$ & $0.64,0.53$ & $0.23,0.82$ & $-1.21,0.24$ & $0.71,0.49$ & $-0.54,0.59$ \\
\hline
\end{tabular}



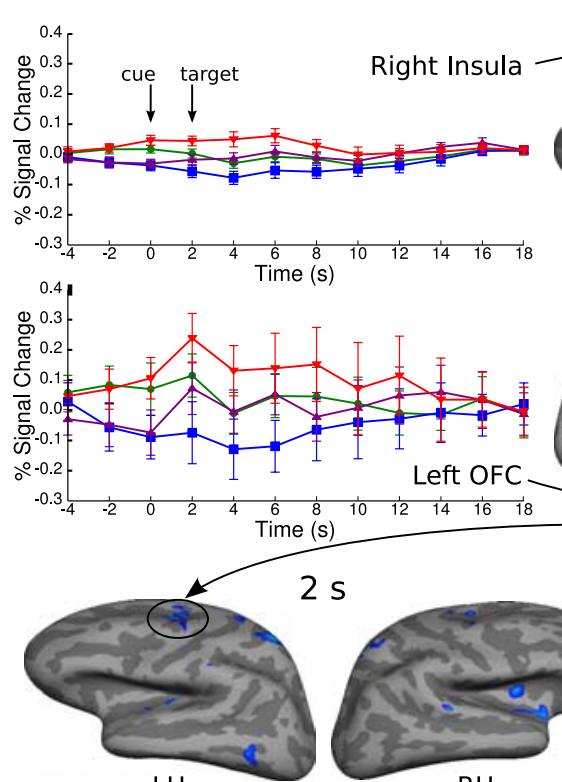

$\mathrm{LH}$

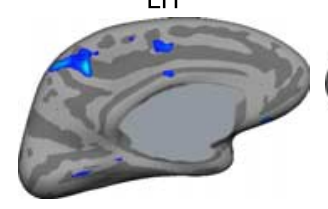

$2 \mathrm{~s}$
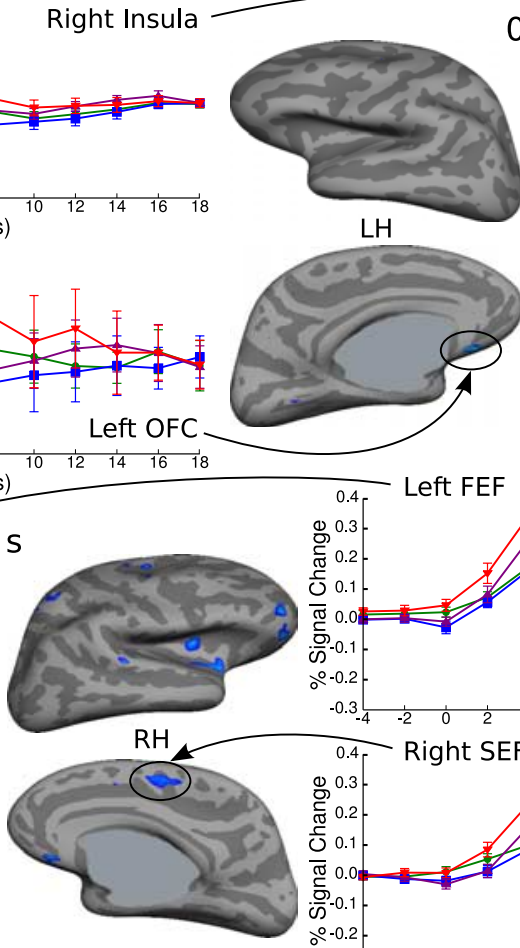

$\mathrm{LH}$
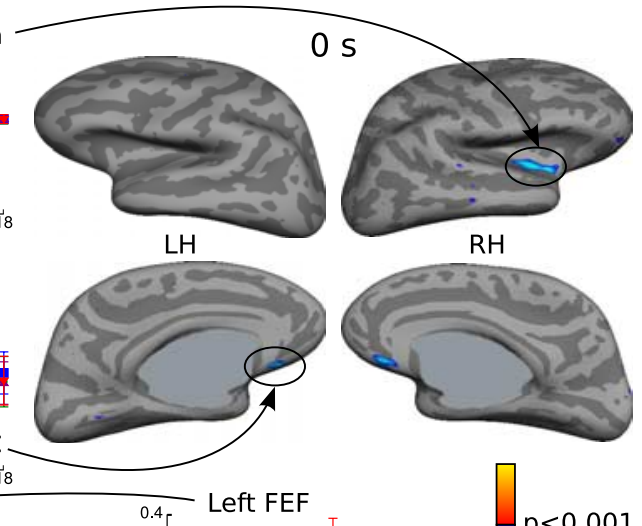

Left OFC

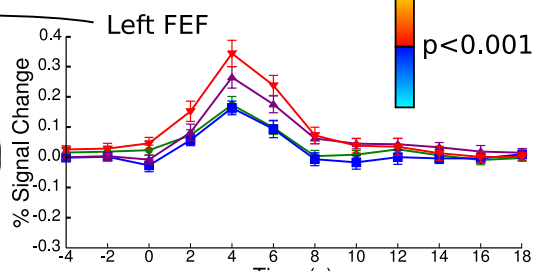

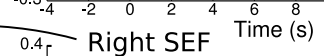
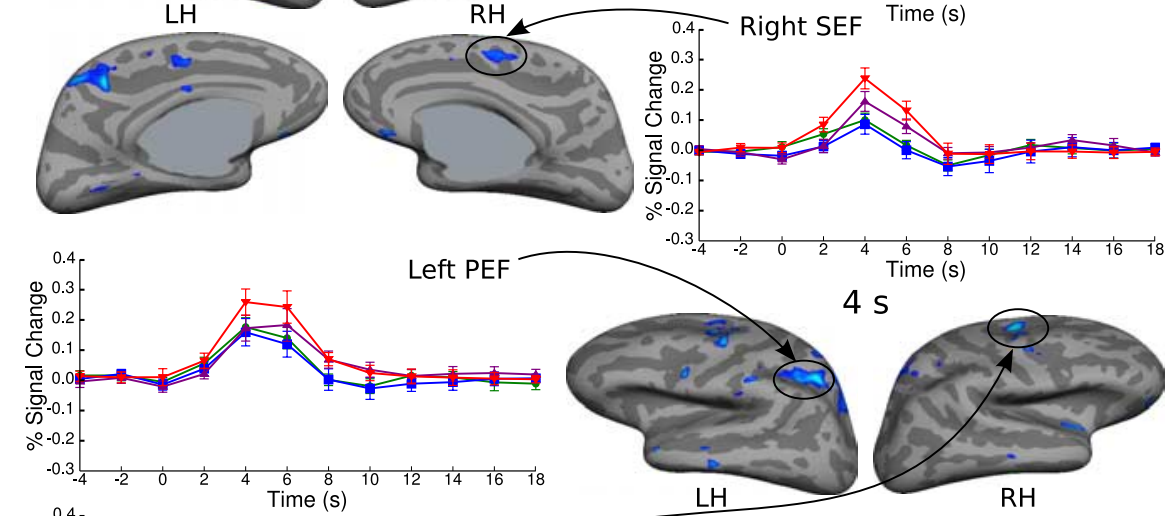

$4 \mathrm{~s}$

6
Time $(s)$ Tim
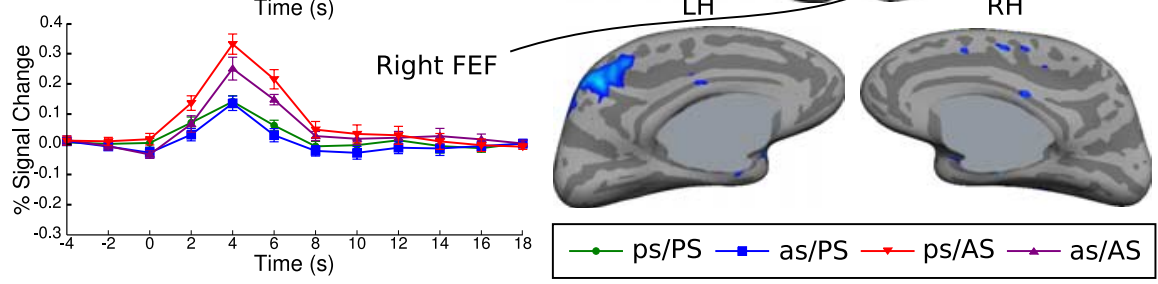

Figure 3. Cortical activation in the exploratory analyses of the registered group data for the contrast of as/AS versus ps/AS at 0 2 , and $4 \mathrm{~s}$ displayed on the lateral and medial views of the inflated cortical surface. Vertices showing reduced activity for a previous antisaccade at a threshold of $p<0.001$ are displayed in blue. There were no regions showing significantly increased activity, which would be displayed in red. The gray masks cover nonsurface regions in which activity is displaced. The hemodynamic Approximate Talairach coordinates are given in Table 2. Time in seconds is on the $x$-axis, and the percentage of signal change relative to the fixation baseline is on the $y$-axis. $\mathrm{LH}$, Left hemisphere; $\mathrm{RH}$, right hemisphere; OFC, orbitofrontal cortex. response time course graphs with SE bars are displayed for vertices with peak activation for each condition in selected regions.

were all significant (see supplemental material, available at www.jneurosci.org). Thus, previous antisaccade effects persisted and were qualitatively similar in magnitude after delays of up to $6 \mathrm{~s}$. This suggests that the finding is not a result of hemodynamic saturation from the residual hemodynamic response of the preceding trial but rather reflects a neural effect elicited by the type of preceding trial.

\section{Discussion}

Our findings demonstrate that the neural response to an event is modulated by recent history. In the wake of a challenging task, the response system seems to "step on the brakes," reducing activation and slowing responses, perhaps as a means of enhancing accuracy. Although this may not have been advantageous during the present experiment because the sequence of trials was randomized to remove predictability, in the real world, events are seldom in a random sequence, and the ability to modulate responses based on immediate experience is critical to adaptive behavior. Specifically, in the context of a saccadic paradigm, we found that relative to a previous prosaccade, an antisaccade in the preceding trial was associated with reduced FEF activity in the current antisaccade trial. We interpret this reduction to reflect the effects of having to inhibit the response system in the previous trial. A previous antisaccade was also associated with activity reductions in the SEF and orbitofrontal cortex, and no region showed increased activity. This provides specific anatomical correlates to the behavioral observation that a previous antisaccade prolongs saccadic latencies (Cherkasova et al., 2002; Fecteau et al., 2004; Barton et al., 2006). These findings demonstrate that trial history shapes ocular motor performance and associated brain activity in a continuous, dynamic manner constituting a form of immediate neural plasticity (Dorris et al., 2000).

The effects of trial history appear to interact with current task demands (i.e., more time to decay. To investigate this possibility, we examined the influence of the intertrial interval on the magnitude of the activity reduction in the FEF for as/AS versus ps/AS trials. We divided ps/AS and as/AS trials with regard to the length of the preceding fixation interval: $0,2,4$, or $6 \mathrm{~s}$. Because there were relatively few trials preceded by 4 and $6 \mathrm{~s}$ of fixation, these trials were combined for analysis. For each participant, we examined activity in FEF vertices that showed a previous antisaccaderelated reduction at $p<0.05$. ANOVAs revealed that the effect of a previous antisaccade did not differ as a function of length of the preceding fixation interval in either hemisphere (interaction of previous saccade type and intertrial interval: left, $F_{(2,13)}=0.80$, $p=0.45$; right, $F_{(2,16)}=0.94, p=0.40$ ), and contrasts of as/AS versus $\mathrm{ps} / \mathrm{AS}$ activity in each hemisphere at each intertrial interval whether a prosaccade or antisaccade was required). For current antisaccades, a previous antisaccade was associated with reduced activity in the FEF at the beginning of the trial, before the target, and this reduction was sustained at 2 and $4 \mathrm{~s}$. For current prosaccades, a previous antisaccade was associated with reduced FEF activity at 0 and $2 \mathrm{~s}$, but this reduction was absent when trials with current and previous errors were excluded. The SEF and PEF also showed reductions from a previous antisaccade that, with the exception of a reduction in the right SEF at $0 \mathrm{~s}$ for prosaccades, were only present for current antisaccades. In the FEF, SEF, and PEF, reciprocally interconnected cortical regions that contribute to saccade generation, the finding that a previous antisaccade affected activity differently for current prosaccades and antisac- 
Table 2. Cortical regions showing significant activation in the exploratory analyses of the registered group data for the contrasts of as/AS versus $\mathrm{ps} / \mathrm{AS}$, as/PS versus $\mathrm{ps} / \mathrm{PS}$, and current $A S$ versus $P S$

\begin{tabular}{|c|c|c|c|c|c|c|c|}
\hline \multirow[b]{2}{*}{ Contrast } & \multirow[b]{2}{*}{ Time point (s) } & \multirow[b]{2}{*}{ Activated regions } & \multicolumn{3}{|c|}{ Talairach coordinates } & \multirow[b]{2}{*}{$t$ value } & \multirow[b]{2}{*}{$p$ value } \\
\hline & & & $x$ & $y$ & $z$ & & \\
\hline \multirow[t]{11}{*}{ as/AS vs ps/AS } & \multirow[t]{3}{*}{0} & Right insula & 35 & -7 & -6 & -7.06 & 7.64E-07 \\
\hline & & Left orbitofrontal cortex & -7 & 25 & -21 & -6.00 & $7.24 \mathrm{E}-06$ \\
\hline & & Right orbitofrontal cortex & 5 & 28 & -19 & -6.00 & 7.87E-06 \\
\hline & \multirow[t]{4}{*}{2} & Left posterior cingulate sulcus & -15 & -39 & 49 & -6.05 & $6.49 \mathrm{E}-06$ \\
\hline & & Left FEF & -25 & 1 & 48 & -6.05 & $6.55 \mathrm{E}-06$ \\
\hline & & Left superior parietal gyrus & -22 & -45 & 60 & -5.46 & $2.38 \mathrm{E}-05$ \\
\hline & & Right SEF & 8 & 2 & 51 & -4.62 & $1.64 \mathrm{E}-04$ \\
\hline & \multirow[t]{4}{*}{4} & Right FEF & 22 & 2 & 52 & -6.77 & $1.38 \mathrm{E}-06$ \\
\hline & & Left PEF & -26 & -51 & 47 & -6.57 & $2.1 \mathrm{E}-06$ \\
\hline & & Left precuneus & -10 & -46 & 49 & -5.66 & $1.53 \mathrm{E}-05$ \\
\hline & & Right superior parietal gyrus & 24 & -52 & 59 & -4.22 & 4.26E-04 \\
\hline \multirow[t]{4}{*}{ as/PS vs ps/PS } & 0 & Right insula & 31 & 23 & -13 & -4.60 & $1.72 \mathrm{E}-04$ \\
\hline & \multirow[t]{3}{*}{2} & Right orbitofrontal cortex & 14 & 32 & -18 & -7.04 & $7.85 \mathrm{E}-07$ \\
\hline & & Right middle temporal gyrus & 61 & -29 & -11 & -6.63 & $1.85 \mathrm{E}-06$ \\
\hline & & Left orbitofrontal cortex & -8 & 29 & -19 & -6.06 & $6.32 \mathrm{E}-06$ \\
\hline \multirow[t]{19}{*}{ AS vs PS } & \multirow[t]{2}{*}{0} & Right posterior cingulate cortex & 23 & -23 & 50 & -5.26 & $9.23 \mathrm{E}-05$ \\
\hline & & Right central sulcus & 13 & -20 & 46 & -4.87 & $3.78 \mathrm{E}-05$ \\
\hline & \multirow[t]{17}{*}{4} & Right SEF & 10 & 10 & 45 & 9.07 & $1.58 \mathrm{E}-08$ \\
\hline & & Left FEF & -28 & 2 & 49 & 8.49 & 4.63E- -08 \\
\hline & & Left SEF & -11 & 14 & 36 & 8.33 & $6.17 \mathrm{E}-08$ \\
\hline & & Right FEF & 30 & -2 & 41 & 8.09 & $9.89 \mathrm{E}-08$ \\
\hline & & Right parietal transverse sulcus & 22 & -56 & 52 & 7.83 & $1.63 \mathrm{E}-07$ \\
\hline & & Left superior parietal gyrus & -12 & -63 & 53 & 6.99 & $8.71 \mathrm{E}-07$ \\
\hline & & Right insula & 30 & 28 & 5 & 6.67 & $1.71 \mathrm{E}-06$ \\
\hline & & Right PEF & 33 & -40 & 37 & 6.44 & $2.81 E-06$ \\
\hline & & Left dorsal anterior cingulate cortex & -3 & 22 & 22 & 6.28 & $3.93 \mathrm{E}-06$ \\
\hline & & Left insula & -27 & 29 & 2 & 6.20 & 4.66E- -06 \\
\hline & & Right subcentral gyrus & 43 & -16 & 19 & -5.58 & $1.85 \mathrm{E}-05$ \\
\hline & & Left PEF & -33 & -34 & 38 & 5.40 & $2.74 \mathrm{E}-05$ \\
\hline & & Right dorsal anterior cingulate cortex & 7 & 15 & 31 & 5.29 & $3.56 \mathrm{E}-05$ \\
\hline & & Left inferior frontal gyrus & -37 & 23 & 8 & 5.20 & $4.33 \mathrm{E}-05$ \\
\hline & & Left superior occipital sulcus & -25 & -84 & 19 & 5.12 & $5.25 \mathrm{E}-05$ \\
\hline & & Left angular gyrus & -39 & -65 & 42 & -4.73 & $1.27 E-04$ \\
\hline & & Left precuneus & -4 & -56 & 15 & -4.47 & $2.34 \mathrm{E}-04$ \\
\hline
\end{tabular}

Talairach coordinates derived from the surface maps, $t$ test values, and $p$ values (in exponents, base 10 ) are given for the vertex with maximal activation across the 0,2 , and $4 \mathrm{~s}$ time points. Regions in bold type are those for which the hemodynamic responses are plotted in Figure 3. Talairach coordinates are approximate and may not always correspond to the surface localizations.

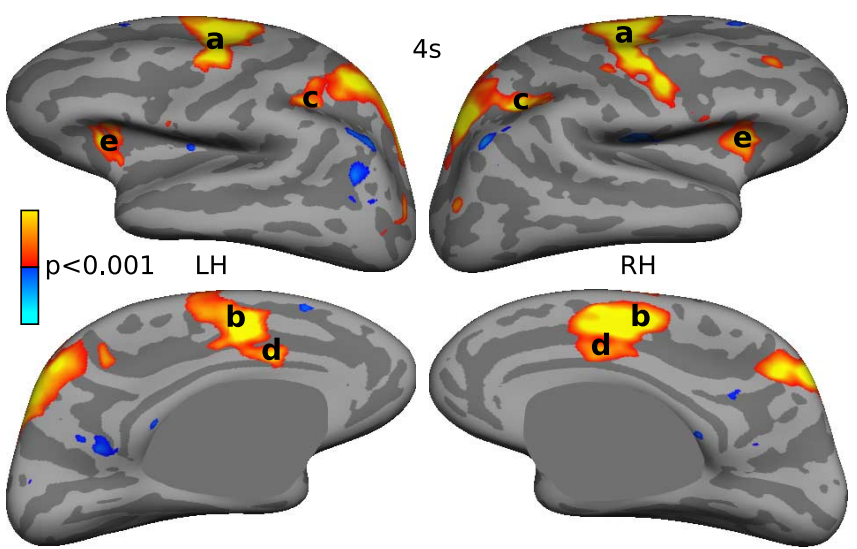

Figure 4. Cortical activation at a threshold of $p<0.001$ for the contrast of antisaccades versus prosaccades at $4 \mathrm{~s}$ displayed on the lateral and medial views of the inflated cortical surfaces of the right hemisphere $(\mathrm{RH})$ and left hemisphere $(\mathrm{LH})$. Significantly increased activity is displayed in red, and decreased activity is displayed in blue. $a, \mathrm{FEF} ; \mathrm{b}, \mathrm{SEF} ; \mathrm{c}, \mathrm{PEF} ; \mathrm{d}$, dorsal anterior cingulate cortex; $\mathrm{e}$, insula.

cades suggests that trial history interacts with current task demands. One interpretation of this pattern of findings is that the cue to perform an antisaccade perpetuated activity reductions necessary for effective inhibition, whereas the cue to perform a prosaccade led them to dissipate.
Could the activity reductions associated with a previous antisaccade instead result from a previous error? There was a higher error rate for antisaccades than prosaccades. Errors can increase response time and accuracy and presumably also alter brain activity in the subsequent trial (Rabbitt, 1966), including for antisaccade tasks (Nieuwenhuis et al., 2001). Excluding both error trials and correct trials preceded by errors from our contrasts examining trial history did not substantially alter the findings for current antisaccades, but for current prosaccades, FEF activity differences were no longer significant. Although this may reflect reduced power because of fewer trials and collinearity in the analysis, the possibility that reduced FEF activity for prosaccades preceded by antisaccades reflects the intertrial effects of errors cannot be excluded. Previous errors, however, cannot account for the prolonged latencies of prosaccades preceded by antisaccades because trials with previous and current errors were not included in the latency analyses.

As in our previous studies, a previous antisaccade prolonged saccadic latencies. This effect was significantly greater for prosaccades than antisaccades, for which it was only a statistical trend. [This more equivocal result for antisaccades in the present study compared to previous ones may reflect the relative insensitivity to small latency differences of the scanner-based eye movement recording system because of the relatively low sampling rate $(60$ $\mathrm{Hz}$ ). A previous behavioral study found a significant $16 \mathrm{~ms}$ difference between switched and repeated antisaccades using a sys- 
tem with a $500 \mathrm{~Hz}$ sampling rate (Cherkasova et al., 2002).] The larger effect for prosaccades likely reflects that latency is influenced by both previous antisaccade and task-switching costs (Barton et al., 2006). When participants change from a prosaccade to an antisaccade or vice versa, this constitutes a switch of tasks. Task switching involves cognitive processes not present when repeating trials and generally incurs both latency and accuracy costs (Allport et al., 1994; Rogers and Monsell, 1995; Meiran et al., 2000). Thus, task-switching latency costs are expected to add to the effect of a previous antisaccade in slowing current prosaccades and subtract from the effect of a previous antisaccade in slowing current antisaccades (Barton et al., 2006). The fact that switched antisaccades are actually faster than repeated ones (paradoxical task-switching benefit, rather than cost) reflects that it is the effect of a previous antisaccade, rather than task switching, that dominates latency costs. The opposite is true for errors. Switched trials, both prosaccades and antisaccades, are associated with a higher error rate than repeated trials in this and previous studies (Cherkasova et al., 2002; Barton et al., 2006). This demonstrates divergent effects of trial history on latency and error rate.

Is it possible that task switching rather than persistent antisaccade effects accounts for the fMRI intertrial effects that we observed? Task switching has been associated with greater activity in task-relevant regions (Swainson et al., 2003). Whereas switched antisaccades had greater activity than repeated ones, switched prosaccades had relatively reduced activity. This difference in the direction of the sign for switched trials is thus more consistent with the effects of a previous antisaccade than with the effects of task switching.

Control analyses ruled out the possibility that our findings were as a result of hemodynamic saturation effects. If the reductions were because of a vascular effect, one would expect them to dissipate with longer intertrial intervals because the hemodynamic response from the previous trial has more time to decay. We examined this possibility explicitly in the FEF and found that the magnitude of the activity reduction for trials preceded by an antisaccade was not affected by the length of the intertrial interval, thus ruling out a vascular explanation of our findings.

We interpret the reduced hemodynamic response in the FEF and longer saccadic reaction times as a result of a previous antisaccade to reflect the effects of having to inhibit the response system in the previous trial. It is important to note, however, that the same FEF region that showed reduced BOLD activity in association with a previous antisaccade showed significantly increased activity for current antisaccades versus prosaccades. The finding of increased BOLD activity in the FEF for antisaccades versus prosaccades is consistent with numerous previous neuroimaging studies (O'Driscoll et al., 1995; Sweeney et al., 1996; Connolly et al., 2002; Ford et al., 2005) and has been interpreted to reflect inhibition of the FEF. These interpretations seem to be contradictory: How can increased BOLD activity with a current antisaccade and reduced BOLD activity with a previous antisaccade both reflect inhibition of FEF neurons? In reconciling these interpretations, we are limited by fundamental ambiguities regarding the source of the BOLD signal and its limited temporal resolution. BOLD activity correlates with local field potentials that reflect the input to a region, interneuron activity, and neuronal spiking (Logothetis et al., 2001; Lauritzen, 2005; Mukamel et al., 2005). A possible reconciliation, then, is that the increased BOLD activity in the FEF during an antisaccade versus prosaccade reflects input from other regions needed to inhibit the prepotent prosaccade response. In this situation, increased BOLD activity does not imply neuronal excitation but a heightened level of input, which in the case of an antisaccade is inhibitory (DeSouza et al., 2003). This explanation also reconciles the apparent discrepancy between single-unit recording findings that antisaccades are associated with reduced preparatory activity in the FEF compared with prosaccades (Everling and Munoz, 2000), whereas fMRI studies show increased preparatory FEF activity for antisaccades. However, in the following trial, the effects of these recent inhibitory inputs may be seen as reduced local or interneuron activity and spiking, and hence as reduced BOLD activity in a trial preceded by an antisaccade versus a prosaccade. Clearly, other interpretations are possible, and a more definitive explanation of the neuronal basis of the finding of reduced BOLD activity in the trial after an antisaccade will require a convergence of information from other techniques.

Finally, although our a priori hypothesis focused on the FEF, the SEF and orbitofrontal cortex were the only regions to show activity reductions for both trial types when error effects were controlled. In contrast to saccade-related neurons in the FEF, which show reduced preparatory discharge for antisaccade versus prosaccade commands that is associated with fewer errors (Everling and Munoz, 2000), those in the SEF show increased activity that predicts accurate performance (Schlag-Rey et al., 1997; Amador et al., 2004). The SEF also shows increased fMRI activity for antisaccade versus prosaccade trials in this and other studies (Brown et al., 2006). If, as has been theorized, the SEF contributes to generating internally versus visually guided eye movements (Everling and Munoz, 2000; Amador et al., 2004), activity reductions in trials after antisaccades could contribute to prolonged saccadic latencies. Clarifying the contribution of these regions to representing information regarding trial history requires additional study.

In summary, our findings demonstrate that neural activity is modulated by trial history and provides specific anatomical correlates to behavioral observations that a previous antisaccade prolongs saccadic latencies (Manoach et al., 2002; Fecteau et al., 2004; Barton et al., 2006). They suggest that intertrial effects are an important source of variability in both behavioral and neuroimaging studies.

\section{References}

Allport A, Styles E, Hsieh S (1994) Shifting intentional set: exploring the dynamic control of tasks. In: Attention and performance (Umilta C, Moscovitch M, eds), pp 421-452. Hillsdale, NJ: Erlbaum.

Amador N, Schlag-Rey M, Schlag J (2004) Primate antisaccade. II. Supplementary eye field neuronal activity predicts correct performance. J Neurophysiol 91:1672-1689.

Barton JJ, Greenzang C, Hefter R, Edelman J, Manoach DS (2006) Switching, plasticity, and prediction in a saccadic task-switch paradigm. Exp Brain Res 168:76-87.

Berman RA, Colby CL, Genovese CR, Voyvodic JT, Luna B, Thulborn KR, Sweeney JA (1999) Cortical networks subserving pursuit and saccadic eye movements in humans: an fMRI study. Hum Brain Mapp 8:209-225.

Bichot NP, Schall JD (2002) Priming in macaque frontal cortex during popout visual search: feature-based facilitation and location-based inhibition of return. J Neurosci 22:4675-4685.

Boynton GM, Engel SA, Glover GH, Heeger DJ (1996) Linear systems analysis of functional magnetic resonance imaging in human V1. J Neurosci 16:4207-4221.

Brown MR, Goltz HC, Vilis T, Ford KA, Everling S (2006) Inhibition and generation of saccades: rapid event-related fMRI of prosaccades, antisaccades, and nogo trials. NeuroImage 33:644-659.

Buckner RL, Goodman J, Burock M, Rotte M, Koutstaal W, Schacter D, Rosen B, Dale AM (1998) Functional-anatomic correlates of object priming in humans revealed by rapid presentation event-related fMRI. Neuron 20:285-296. 
Burock MA, Dale AM (2000) Estimation and detection of event-related fMRI signals with temporally correlated noise: a statistically efficient and unbiased approach. Hum Brain Mapp 11:249-260.

Cherkasova MV, Manoach DS, Intriligator JM, Barton JJ (2002) Antisaccades and task-switching: interactions in controlled processing. Exp Brain Res 144:528-537.

Collins DL, Neelin P, Peters TM, Evans AC (1994) Automatic 3D intersubject registration of MR volumetric data in standardized Talairach space. J Comput Assist Tomogr 18:192-205.

Connolly JD, Goodale MA, Menon RS, Munoz DP (2002) Human fMRI evidence for the neural correlates of preparatory set. Nat Neurosci 5:1345-1352.

Connolly JD, Goodale MA, Goltz HC, Munoz DP (2004) FMRI activation in the human frontal eye field is correlated with saccadic reaction time. J Neurophysiol 94:605-611.

Cox RW, Jesmanowicz A (1999) Real-time 3D image registration for functional MRI. Magn Reson Med 42:1014-1018.

Curtis CE, D'Esposito M (2003) Success and failure suppressing reflexive behavior. J Cogn Neurosci 15:409-418.

Dale AM (1999) Optimal experimental design for event-related fMRI. Hum Brain Mapp 8:109-140.

Dale AM, Buckner RL (1997) Selective averaging of rapidly presented individual trials using fMRI. Hum Brain Mapp 5:329-340.

Dale AM, Fischl B, Sereno MI (1999) Cortical surface-based analysis. I. Segmentation and surface reconstruction. NeuroImage 9:179-194.

DeSouza JF, Menon RS, Everling S (2003) Preparatory set associated with pro-saccades and anti-saccades in humans investigated with event-related FMRI. J Neurophysiol 89:1016-1023.

Doricchi F, Perani D, Inoccia C, Grassi F, Cappa SF, Bettinardi V, Galati G, Pizzamiglio L, Fazio F (1997) Neural control of fast-regular saccades and antisaccades: an investigation using positron emission tomography. Exp Brain Res 116:50-62.

Dorris MC, Pare M, Munoz DP (2000) Immediate neural plasticity shapes motor performance. J Neurosci 20:RC52(1-5).

Durston S, Thomas KM, Worden MS, Yang Y, Casey BJ (2002) The effect of preceding context on inhibition: an event-related fMRI study. NeuroImage 16:449-453.

Everling S, Munoz DP (2000) Neuronal correlates for preparatory set associated with pro-saccades and anti-saccades in the primate frontal eye field. J Neurosci 20:387-400.

Everling S, Dorris MC, Klein RM, Munoz DP (1999) Role of primate superior colliculus in preparation and execution of anti-saccades and prosaccades. J Neurosci 19:2740-2754.

Fecteau JH, Munoz DP (2003) Exploring the consequences of the previous trial. Nat Rev Neurosci 4:435-443.

Fecteau JH, Au C, Armstrong IT, Munoz DP (2004) Sensory biases produce alternation advantage found in sequential saccadic eye movement tasks. Exp Brain Res 159:84-91.

Fischer B, Breitmeyer B (1987) Mechanisms of visual attention revealed by saccadic eye movements. Neuropsychologia 25:73-83.

Fischl B, Sereno MI, Dale AM (1999a) Cortical surface-based analysis. II: Inflation, flattening, and a surface-based coordinate system. NeuroImage 9:195-207.

Fischl B, Sereno MI, Tootell RB, Dale AM (1999b) High-resolution intersubject averaging and a coordinate system for the cortical surface. Hum Brain Mapp 8:272-284.

Fischl B, van der Kouwe A, Destrieux C, Halgren E, Segonne F, Salat DH, Busa E, Seidman LJ, Goldstein J, Kennedy D, Caviness V, Makris N, Rosen B, Dale AM (2004) Automatically parcellating the human cerebral cortex. Cereb Cortex 14:11-22.

Ford KA, Goltz HC, Brown MR, Everling S (2005) Neural processes associated with antisaccade task performance investigated with event-related FMRI. J Neurophysiol 94:429-440.

Forman SD, Cohen JD, Fitzgerald M, Eddy WF, Mintun MA, Noll DC (1995) Improved assessment of significant activation in functional magnetic res- onance imaging (fMRI): use of a cluster-size threshold. Magn Reson Med 33:636-647.

Hallett PE (1978) Primary and secondary saccades to goals defined by instructions. Vision Res 18:1279-1296.

Koyama M, Hasegawa I, Osada T, Adachi Y, Nakahara K, Miyashita Y (2004) Functional magnetic resonance imaging of macaque monkeys performing visually guided saccade tasks: comparison of cortical eye fields with humans. Neuron 41:795-807.

Lauritzen M (2005) Reading vascular changes in brain imaging: is dendritic calcium the key? Nat Rev Neurosci 6:77-85.

Logothetis NK, Pauls J, Augath M, Trinath T, Oeltermann A (2001) Neurophysiological investigation of the basis of the fMRI signal. Nature 412:150-157.

Manoach DS, Lindgren KA, Cherkasova MV, Goff DC, Halpern EF, Intriligator J, Barton JJS (2002) Schizophrenic subjects show deficient inhibition but intact task-switching on saccadic tasks. Biol Psychiatry $51: 816-826$.

Meiran N, Chorev Z, Sapir A (2000) Component processes in task switching. Cognit Psychol 41:211-253

Miezin FM, Maccotta L, Ollinger JM, Petersen SE, Buckner RL (2000) Characterizing the hemodynamic response: effects of presentation rate, sampling procedure, and the possibility of ordering brain activity based on relative timing. NeuroImage 11:735-759.

Mukamel R, Gelbard H, Arieli A, Hasson U, Fried I, Malach R (2005) Coupling between neuronal firing, field potentials, and FMRI in human auditory cortex. Science 309:951-954.

Nieuwenhuis S, Ridderinkhof KR, Blom J, Band GP, Kok A (2001) Errorrelated brain potentials are differentially related to awareness of response errors: evidence from an antisaccade task. Psychophysiology 38:752-760.

O'Driscoll GA, Alpert NM, Matthysse SW, Levy DL, Rauch SL, Holzman PS (1995) Functional neuroanatomy of antisaccade eye movements investigated with positron emission tomography. Proc Natl Acad Sci USA 92:925-929.

Paus T (1996) Location and function of the human frontal eye-field: a selective review. Neuropsychologia 34:475-483.

Pierrot-Deseilligny C, Muri RM, Ploner CJ, Gaymard B, Rivaud-Pechoux S (2003) Cortical control of ocular saccades in humans: a model for motricity. Prog Brain Res 142:3-17.

Rabbitt PM (1966) Errors and error correction in choice-response tasks. J Exp Psychol 71:264-272.

Rogers RD, Monsell S (1995) Costs of a predictable switch between simple cognitive tasks. J Exp Psychol 124:207-231.

Schachter SC (1994) Ambilaterality: definition from handedness preference questionnaires and potential significance. Int J Neurosci 77:47-51.

Schlag-Rey M, Amador N, Sanchez H, Schlag J (1997) Antisaccade performance predicted by neuronal activity in the supplementary eye field. $\mathrm{Na}-$ ture 390:398-401.

Straube A, Riedel M, Eggert T, Müller N (1999) Internally and externally guided voluntary saccades in unmedicated and medicated schizophrenic patients. Part I. Saccadic velocity. Eur Arch Psychiatry Clin Neurosci 249:1-6.

Swainson R, Cunnington R, Jackson GM, Rorden C, Peters AM, Morris PG, Jackson SR (2003) Cognitive control mechanisms revealed by ERP and fMRI: evidence from repeated task-switching. J Cogn Neurosci 15:785-799.

Sweeney JA, Mintun MA, Kwee S, Wiseman MB, Brown DL, Rosenberg DR, Carl JR (1996) Positron emission tomography study of voluntary saccadic eye movements and spatial working memory. J Neurophysiol $75: 454-468$.

Thesen S, Heid O, Mueller E, Schad LR (2000) Prospective acquisition correction for head motion with image-based tracking for real-time fMRI Magn Reson Med 44:457-465.

Wager TD, Vazquez A, Hernandez L, Noll DC (2005) Accounting for nonlinear BOLD effects in fMRI: parameter estimates and a model for prediction in rapid event-related studies. NeuroImage 25:206-218. 